\title{
LA LEY GENERAL DE EDUCACIÓN EN LA MEMORIA: DEL RECONOCIMIENTO A LA NEGACIÓN
}

\author{
The General Education Act in Memory: \\ from recognition to denial
}

\section{Patricia Delgado-Granados ${ }^{\alpha}$}

Fecha de recepción: 28/10/2020 • Fecha de aceptación: 12/01/2021

Resumen. El objetivo de este trabajo es analizar el proceso de elaboración de la Ley General de Educación (LGE), gestada en pleno franquismo y promulgada unos años previos a la transición española a un régimen democrático-constitucional. Para ello, se presta especial atención al momento socioeconómico en el que se proyecta y a las diferentes tendencias políticas que irrumpen en el escenario dictatorial y que serán patentes en la transición. Pero también se examinan las experiencias y estrategias individuales y colectivas de otros sectores de la población, mostrando cómo se pasó del reconocimiento a la negación de la LGE. Su puesta en marcha fue el resultado de un diagnóstico crítico del sistema educativo que implicó un cambio decisivo en la situación de la enseñanza, al fijar las condiciones legales para la normalización de la educación universal en España. Se partía de la creencia que la mejora educativa implicaría el desarrollo socioeconómico del país, a la vez que resolvería la situación de conflicto ideológico, político y social irresuelto por la dictadura que se solventaría, en parte, a partir de 1978.

Palabras clave: Ley General de Educación (1970); Política Educativa; Franquismo y educación; Memoria histórica; España.

Abstract. The aim of this paper is to analyze the process of the drawing up of the General Education Act (LGE), created under the Franco regime and implemented a few years before the Spanish transition. In order to do so, we pay special attention to the socio-economic moment in which the law was

\footnotetext{
a Dpto. de Teoría e Historia de la Educación y Pedagogia Social. Área de Teoría e Historia de la Educación, Facultad de Ciencias de la Educación, Universidad de Sevilla. C. Pirotecnia, s/n, 41013 Sevilla, España.patdelgado@us.es (1D https://orcid.org/0000-0002-4717-3406
} 
projected and to the different political tendencies that were emerging in the scenario of dictatorship and that would become more visible in the transition. The paper also examines the individual and collective experiences and strategies of other sectors of the population, showing how they swung from recognition to denial of the LGE. The law's implementation was the result of a critical diagnosis of the education system that implied a need for decisive change in the situation of education, a change that could be achieved by setting legal conditions for the normalization of universal education in Spain. The starting point was the belief that improving education would lead to the socio-economic development of the country while at the same time resolving the situation of ideological, political and social conflict that persisted under the dictatorship and that would be solved, in part, after 1978.

Keywords. General Education Act (1970); Politics Education; Francoism and education; Historical Memory; Spain.

\section{INTRODUCCIÓN}

El filósofo alemán Walter Benjamin en su obra «Infancia en Berlín hacia 1900» recurre a la memoria para deslumbrar ante tanta oscuridad la esencia del pasado perdido, que subsiste como una fuerza redentora y, a su vez, protectora del olvido, ya que: «jamás podremos rescatar del todo lo que olvidamos. Quizás esté bien así. El choque que produciría recuperarlo sería tan destructor que al instante deberíamos dejar de comprender nuestra nostalgia». ${ }^{1}$ Desde esa visión benjaminiana, imbuida de improntas hermenéuticas, pilota este artículo con objeto de poner de manifiesto el valor de la historia a través del estudio de la LGE que, con sus luces y sus sombras, constituyó una de las aportaciones en materia de política educativa más importantes e innovadoras del siglo XX en España. No sería excesivo afirmar que fue una ley bisagra que estableció las bases del sistema educativo español de los años últimos y posteriores a la dictadura. Por último, se analizan las posibles razones que han llevado del reconocimiento que siguió a la ley a su negación, borrando de la memoria colectiva su recuerdo y abocándola al olvido. ${ }^{2}$

\footnotetext{
1 Walter Benjamin, Escritos autobiográficos, trad. Teresa Rocha Marco (Madrid: Alianza Editorial, 1996), 200. Precisamente en ese afán recordatorio en este año se cumplen ochenta años de su muerte.

2 Paul Ricoeur, La memoria, la historia, el olvido (Buenos Aires: F.C.E., 2004). Asimismo, Le Goff analiza la problemática en la construcción de la memoria colectiva en cuanto a la preservación del patrimonio y las prácticas sociales de conmemoración. Jacques Le Goff, El orden de la memoria. El
} 
En este sentido, en la línea de Paul Ricoeur sobre la dialéctica de la memoria y el recuerdo, el reconocimiento es entendido como «una estructura del sí que se refleja en el movimiento que lleva la estima de sí hacia la solicitud, y a ésta hacia la justicia. El reconocimiento introduce la díada y la pluralidad en la constitución misma del sí». ${ }^{3}$ Es, por tanto, una práctica redentora que intenta rescatar del olvido ese pasado, incorporándolo en el presente. A la vez que se asocia a una manera de identificar el pasado desde una impronta actual y, por tanto, novedosa, que lleva implícita su rememoración. Puede decirse, como señala Karl Mannheim, que en la memoria permanecen tanto el recuerdo vivido a nivel personal, es decir individualmente obtenido, como el adquirido, del que nos apropiamos a nivel colectivo. ${ }^{4}$ En cualquier caso, como nos recuerda Viñao Frago, «la memoria salvo casos excepcionales de aislamiento es siempre una memoria compartida». Una memoria que, como señala el autor, se complica cuando añadimos el componente generacional y se cristaliza en el ámbito escolar, ya que "puede decirse que uno se define académicamente por el plan de estudios por el que cursó la segunda enseñanza». ${ }^{5}$ Han pasado cincuenta años de la promulgación de la controvertida LGE. En este contexto conmemorativo el objetivo de las páginas que siguen es trazar una visión reflexiva sobre la reforma, atendiendo a los debates e interpretaciones generados durante su proceso y desarrollo normativo, a las aportaciones más novedosas, así como a sus limitaciones y retos. Su aprobación supuso un salto cualitativo sin precedentes en la educación española al incorporar funciones, principios, objetivos y concepciones que, al menos desde el plano teórico, se asemejaban a los de las sociedades capitalistas. Aunque este giro no implicó perder los rasgos ideológicos del régimen. ${ }^{6}$

tiempo como imaginario (Barcelona: Paidós, 1991). Y Fernández Soria lo materializa en la historia de la educación. Juan Manuel Fernández Soria, «Usos y dimensión moral de la memoria y el olvido en la historia de la educación». Sarmiento 10 (2006): 25-58.

3 Paul Ricoeur, Sí mismo como otro (México: Siglo XXI, 1996), 327. Enzo Traverso, El pasado, instrucciones de uso (Buenos Aires: Prometeo, 2007).

4 Karl Mannheim, «El problema de las generaciones», REIS 62 (1993): 214.

5 Antonio Viñao Frago, «Ayer y hoy de la educación en España. Memorias y desmemorias», en Lecciones contra el olvido. Memoria de la educación y educación de la memoria, ed. Carlos Lomas (Madrid: Octaedro, 2011), 15.

6 Manuel de Puelles Benítez, «Tecnocracia y política en la reforma educativa de 1970», Revista de Educación n. ${ }^{\circ}$ ext. "La Ley General de Educación veinte años después» (1992): 24. El franquismo representa uno de los períodos de la historia de España más investigados y controvertidos. Su amplia dimensión 
En este sentido, el presente trabajo pretende aportar elementos de reflexión que ayuden a «una más profunda comprensión tanto del pasado como del presente», ${ }^{7}$ analizando la LGE en relación con los cambios que a todos los niveles -políticos, económicos y sociales- se estaban produciendo en la España del desarrollismo económico franquista. Entendemos que la forma en la que se produjo la reforma educativa estuvo condicionada por el contexto interno de los sectores dirigentes del régimen y las presiones externas, ya que como nos recuerdan Espigado y Cabrera «las leyes educativas deben ser revisadas desde las tradiciones culturales en las que se insertan, que aluden a las formas de concebir la sociedad y el individuo en ella». 8 Por último, se analizan los posibles factores que han llevado a su olvido y negación en la memoria colectiva. Curiosamente cuando representa una de las reformas educativas más importantes promulgadas en España, no solo por sus veinte años de vigencia, siendo el referente normativo del siglo XX en cuanto que reguló todo el sistema educativo español, sino por motivos sustanciales como fue la integración de un conjunto de principios, funciones, objetivos y estructura organizativa acorde a los estándares internacionales. ${ }^{9}$

\section{EL CONDICIONAMIENTO POLÍTICO EN ESPAÑA: DEL AISLAMIENTO AUTÁRQUICO AL DESARROLLISMO ECONÓMICO FRANQUISTA}

En líneas generales, el condicionamiento político ha guardado una estrecha relación con las dictaduras en las que se ha aplicado. En el caso de España, las bases del régimen franquista se sustentaron en una dictadura militar autoritaria de partido único, el Movimiento Nacional, en el que se centralizaron todas las facciones derechistas que apoyaron el golpe de Estado de 1936 -principalmente monárquicos, tanto carlistas como alfonsinos, falangistas y corporativistas católicos, junto al Ejército

\footnotetext{
temporal, casi cuarenta años, ha permitido disponer de abundantes estudios. No obstante, esta abundancia bibliográfica se ha centrado principalmente en la guerra civil y posguerra, produciéndose un desequilibrio en cuanto a los estudios dedicados a las décadas finales del régimen. Julio Arostégui Sánchez, «La historiografía sobre la España de Franco. Promesas y debilidades», Historia Contemporánea 7 (1992): 79.

7 Edward H. Carr, ¿Qué es la historia? (Barcelona: Ariel Historia, 2003), 91.

8 Gloria Espigado Tocino y Blas Cabrera Montoya, «Las leyes educativas de la democracia en España a examen (1980-2013)», Historia y Memoria de la Educación 3 (2016): 9.

9 Carlos Lerena Alesón, Escuela, ideología y clases sociales. Barcelona: Ariel, 1976.
} 
y la Iglesia católica-. Estas tres piedras angulares -Movimiento Nacional, Ejército e Iglesia- rigieron el devenir del país durante casi más de cuarenta años. Durante ese tiempo no fueron pocas las tensiones entre los grupos políticos ni tampoco escasas las que se produjeron entre los diferentes sectores dentro del partido único. ${ }^{10}$ Ello provocó que esta coalición de facciones resultara en muchas ocasiones incómoda, pues partían de supuestos ideológicos diferentes que no tenían siempre los mismos intereses en relación con el gobierno de la nación. En cualquier caso, esta particular unión, tan centralizada como atomizada, dio lugar al llamado nacional-sindicalismo católico conformado por una tupida red de relaciones por la que pasaban las distintas jefaturas de Falange, sindicatos, organización juvenil... Todo ello, con el objetivo de encuadrar y controlar a la sociedad mediante los aparatos ideológicos y represivos del Estado y la exaltación de valores relacionados con el orden, la jerarquía y la disciplina.

Ciertamente los rasgos básicos que caracterizaron al Nuevo Estado de orientación totalitaria fueron el antiliberalismo, el antiparlamentarismo, la concentración de poderes en Franco, el control de los medios de comunicación, el partido único, la represión, etc. ${ }^{11}$ Desde el primer momento, se estableció una dictadura soberana que suprimió los derechos fundamentales de los ciudadanos y eliminó la división de poderes. ${ }^{12}$ En consecuencia, el franquismo no se puede definir como un Estado de derecho, sino un Estado con derecho. ${ }^{13}$ Así queda recogido en el artículo primero del Fuero de los Españoles, promulgado el 17 de julio de 1945 y aprobado por las Cortes con carácter de Ley Fundamental:

El Estado Español proclama como principio rector de sus actos, el respeto a la dignidad, la integridad y la libertad de la persona

\footnotetext{
10 Benjamín Oltra y Amando De Miguel, «Bonapartidismo y catolicismo: una hipótesis sobre los orígenes ideológicos del franquismo», Papers: Revista de Sociologia 8 (1978): 53-102. Borja de Riquer, La dictadura de Franco. Volumen 9 (Barcelona: Crítica Marcial Pons, 2010).

11 Manuel Ramírez Jiménez, España 1939-1975. Régimen político e ideología (Barcelona: Labor, 1978). No se pretende abrumar al lector con multitud de datos, sino destacar algunas características de la dictadura franquista que entendemos son necesarias reseñar para contextualizar el tema de estudio planteado.

12 Manuel de Puelles Benítez, «Oscilaciones de la política educativa en los últimos cincuenta años: Reflexiones sobre la orientación política de la educación», Revista Española de Pedagogía 192 (1992): 312.

13 Álvaro Soto Carmona y Pedro A. Martínez Lillo, «La naturaleza del franquismo», El País, 8 de junio de 2011.
} 
humana, reconociendo al hombre, en cuanto portador de valores eternos y miembro de una comunidad nacional, titular de deberes y derechos, cuyo ejercicio garantiza en orden al bien común. ${ }^{14}$

Puede decirse, como señala Julio Aróstegui, que el régimen franquista representó perfectamente el concepto de «espacio de inteligibilidad o espacio social», entendido como «aquel lapso de tiempo en el que una combinación determinada y bien caracterizada de factores ambientales, ecológicos, económicos, culturales y políticos, y todos los demás pertinentes, permanece conformando un sistema de algún tipo, cuyo modelo puede ser establecido». ${ }^{15}$ De acuerdo con lo anterior, y dado que el régimen franquista se prolongó casi cuatro décadas -desde el fin de la guerra civil en 1939 hasta la muerte de Franco en 1975- experimentando cambios relevantes, resulta necesario acudir a su periodización, aunque sea en un sentido conceptual y flexible con objeto de poder contextualizar, con cierto grado de sistematicidad, los factores coyunturales sociales, políticos y económicos que impulsaron la LGE. Teniendo en cuenta además que la gestión política del régimen fue cada vez más compleja y camaleónica al coexistir con las épocas fascistas y naional-católica posfascista. ${ }^{16}$ Para ello, recurrimos a la periodización del hispanista británico Paul Preston que distingue: 1) el Período Azul, entre 1936 y 1945, de marcado carácter imperialista y fascista; 2) el Período del Corporativismo Nacional Católico, entre 1945 y 1959; y, 3) el Período del Desarrollismo o de la Tecnocracia, entre 1959 y 1975, en el que se enmarca cronológicamente el presente estudio. ${ }^{17}$

\footnotetext{
14 Representó, dentro de las leyes fundamentales del franquismo, «el texto fundamental definidor de los derechos y deberes de los españoles y amparador de sus garantías». BOE, núm. 199, de 18 de julio de 1945.

15 Julio Aróstegui Sánchez, La investigación histórica: teoría y método (Barcelona: Crítica, 1995), 227.

16 Aunque el régimen se caracterizó por su carácter aparentemente camaleónico, nunca varió en su esencia despótica y fascista -dictadura personal de origen bélica y militar-. Enrique Moradiellos García, «Franco, el Caudillo: origen y perfil de una magistratura política carismática», Historia y Política 35 (2016): 280.

17 Paul Preston, Franco: Caudillo de España (Madrid: Debate, 2015). Stanley G. Payne señala igualmente tres fases: «semifascista y potencialmente imperialista» (1936-1945), "corporativista y nacionalcatólica» (1945-1957/1959), y «desarrollista tecnocrática y autoritario burocrática» (1959-1975). Stanley G. Payne, El régimen de Franco, 1936-1975 (Madrid: Alianza Editorial, 1987), 651. Al igual que el historiador Manuel Ramírez que clasifica estas etapas en: «régimen totalitario», «dictadura empírico-conservadora» y "franquismo tecnopragmático», respectivamente. Manuel Ramírez Jiménez, España 1939-1975. Régimen político e ideología (Barcelona: Labor, 1978), 25.
} 
En líneas generales, los dos primeros períodos se caracterizaron por la penuria económica y la búsqueda de un modelo de autosuficiencia mediante la intervención del Estado. Esta propuesta de política autárquica en la que se trataba de proteger la producción nacional de la demanda exterior estuvo influenciada por la Italia de Mussolini y la Alemania de Hitler. Con los años estos intentos autárquicos acabarían abandonándose por su inviabilidad, dando lugar a la última etapa que se inicia con el Plan de Estabilización en 1959 y se extiende hasta 1975.18 Uno de sus rasgos característicos fue la culminación del proceso modernizador, iniciado en la década de los cincuenta, y la instauración, a partir de los sesenta, del modelo tecnocrático con el tardo-franquismo, la crisis económica y la agonía del régimen. ${ }^{19}$ Los estímulos liberalizadores y los sucesivos Planes de Desarrollo permitieron la creación de nuevos sectores industriales. Lo que originó, en muchos casos, una mejora en el nivel de vida de la población. Nacía así una clase media hasta entonces casi inexistente a la que no le había tocado vivir la situación de máxima represión ideológica del período autárquico, en especial durante el Período Azul. ${ }^{20}$ No obstante, esta apertura económica no vino acompañada de un avance social. ${ }^{21}$

El descontento generalizado por la falta de libertades contribuyó a un aumento de las manifestaciones callejeras, revueltas estudiantiles y huelgas obreras, que se extendieron a lo largo de la década de los sesenta. Parte de esta oposición al régimen lo conformaron las nuevas generaciones ajenas a las secuelas de la fratricida guerra e inmediata posguerra

\footnotetext{
18 El Vicesecretario General del Movimiento, José Miguel Ortí Bordás, afirmaba en 1969 que «la revolución se llama hoy desarrollo». Miguel Ángel Rebollo Torío, Vocabulario político republicano y franquista, 1931-1971 (Valencia: Fernando Torres Editor, 1978).

19 El llamado modelo tecnocrático arrancó en el gobierno de 1957 con Laureano López Rodó, impulsor de los Planes de Desarrollo y del importante cambio de rumbo en la política económica del país, destacando por su papel en el ascenso en el gobierno de Franco de los miembros del Opus Dei. Fabián Estapé, De tots colors: Memories (Barcelona: Editions 62, 2000), 57.

20 Benigno Delmiro Coto, La rebelión de la cultura en Asturias: Las sociedades culturales frente al franquismo (Oviedo: KRK Ediciones, 2019).

21 Respecto al debate político, aún no resuelto, en torno a la tecnocracia en el mundo occidental, Puelles Benítez nos recuerda que España, al carecer de un régimen democrático, el término tecnocracia se utilizó para «referirse fundamentalmente a un grupo de personas que tenían unas características comunes, especialmente su pertenencia, directa o indirecta, a un grupo religioso determinado. Se importaba así un debate (¿quién lo importaba?, ¿con qué fines?) al que, en rigor, éramos ajenos; es decir, se falseaba de entrada el problema». Puelles Benítez, «Tecnocracia y política en la reforma educativa de 1970», 15.
} 
y con nuevas formas de protesta que ponían en cuestión el sistema de control social de la dictadura. ${ }^{22}$ Las huelgas fueron cada vez más numerosas en las zonas industriales siendo las más conflictivas Barcelona, Madrid, País Vasco y Asturias, y por sectores la minería, la metalurgia y la construcción. A final de la década de los sesenta, las protestas se extendieron a otras provincias, incluso sin tradición obrerista, y en nuevos sectores como el automóvil, participando también grupos de las clases medias. ${ }^{23}$ Supuso, por tanto, uno de los períodos más críticos de lucha por las libertades y los derechos sociales comprobando cómo lo acontecido durante los años previos a la aprobación de la ley, y posterior crisis del franquismo, constituye un espacio de análisis esencial para entender las posibles razones de este balance agridulce de la LGE.

\section{EL DESFASE ENTRE POLÍTICA Y SOCIEDAD: LA AGONÍA DEL RÉGIMEN FRANQUISTA}

En efecto; el rápido crecimiento económico y la modernización del país fueron los primeros indicadores de la instauración del modelo tecnocrático que, en cierto modo, compensaron dos décadas de regresión y aislamiento con el resto de países europeos. En términos estratégicos, como ha señalado Julián Santamaría, se trataba de "poner en práctica un nuevo mecanismo de integración» de las fuerzas políticas de apoyo al régimen, es decir, de las distintas «familias» del régimen, con objeto de mantener el equilibrio del Estado bélicamente alzado e intervenir en momentos socialmente conflictivos. ${ }^{24}$ La puesta en marcha de la nueva orientación económica del país pasaba por la dirección tecnocrática de los ministerios e instituciones determinantes. Para ello, el nuevo

\footnotetext{
22 Para Xavier Domènech la década de los años sesenta representó una etapa conformadora del nuevo movimiento obrero en el que participaron las organizaciones tradicionales de la posguerra a las que habían pertenecido sus padres con las de las nuevas generaciones. Xavier Domènech Sampere, «La formación de la clase obrera bajo el franquismo. Nuevos debates», Ayer 79, no. 3 (2020): 283-296.
}

23 Además de estos factores, otro aspecto esencial en la represión franquista fue la depuración profesional como herramienta no solo para castigar a los vencidos, sino también para construir el nuevo régimen. La persecución, la represión y la violencia para someter a la oposición fueron una práctica habitual en el proyecto de exterminio del adversario político y de ordenación de la sociedad y del Estado. Josefina Cuesta (dir.), La depuración de funcionarios bajo la dictadura franquista (19361975) (Madrid: Fundación Largo Caballero, 2009). Michael Richards, Un tiempo de silencio. La guerra civil y la cultura de la represión en la España de Franco, 1936-1945 (Barcelona: Crítica, 1999).

24 Julián Santamaría Ossorio (comp.), En transición a la democracia en el Sur de Europa y América Latina. Colección monográfica (Madrid: CSIC, 1982), 68. 
gobierno que había salido de la crisis ministerial de 1957, desplazando a los católicos de la Asociación Católica Nacional de Propagandistas (ACNP), adoptó una serie de medidas de estabilización económica para contener la inflación y la presión de las instituciones financieras internacionales (Banco Mundial, FMI y OECE, actualmente OCDE). Como señalan Carreras y Tafunell, coincidiendo con García Delgado, España había vivido desde la guerra civil hasta 1950 una auténtica depresión económica, pero a partir de los años sesenta se sumó al crecimiento industrial de Europa. ${ }^{25}$ En efecto, la expansión económica, atribuible a los Planes de Estabilización (1959-1969) y favorecida por el ciclo expansivo de la economía europea, conllevó una mayor demanda educativa instaurándose lo que se denominó modelo «tecnopragmático» orientado a vincular la educación como un bien de consumo y de crecimiento económico. ${ }^{26}$ Sin embargo, España seguía arrastrando los problemas derivados de la insuficiencia de las enseñanzas medias de tipo técnico, la formación profesional y la necesidad de mano de obra cualificada en el sector industrial y de servicios. ${ }^{27}$ Así se refleja en el Informe del Banco Mundial donde se apuntaba la urgencia por parte del Estado español de:

[...] proveer una base de enseñanza profesional y técnica para aquellos que continúen su educación (después de la primaria). Durante el proceso de modernización de la economía [...] las técnicas cambiarán constantemente, y son importantes la flexibilidad mental y la adaptabilidad en la utilización de especializaciones [...] Una buena educación general es indispensable para todo ello. ${ }^{28}$

\footnotetext{
25 Albert Carreras y Xavier Tafunell, Estadísticas históricas de España. Siglos XIX-XX. 3 volúmenes (Madrid: Fundación BBVA, 2006). José Luis García Delgado, La economía española durante el franquismo (Barcelona: Temas para el Debate, 1995).

26 Ramírez, España 1939-1975. Régimen político e ideología, 25.

27 Así se recogía en el II Informe FOESSA de 1966 en el que se hacía hincapié tanto en el sector agrario como educativo, considerados prioritarios en el II Plan de Desarrollo (1968-1971). Hay que tener en cuenta que la Fundación FOESSA (Fomento de Estudios Sociales y Sociología Aplicada) se crea en 1965, impulsada por Cáritas Española, con el objetivo principal de analizar la situación social de España mediante estudios sociológicos globales que evidenciaran los factores de crisis. Es decir, estos estudios no pretendían ser un mero informe descriptivo de la estructura social del país, sino que se adentraban en el análisis de los problemas básicos de la sociedad española. Durante la dictadura se llegaron a publicar 3 informes, el primer estudio global en octubre de 1966, el segundo en 1970 y el tercero en 1975. FOESSA, Informe sociológico sobre la situación social en España (Madrid: Euroamérica, 1966), 15.

28 VV. AA., Informe del Banco Internacional de Reconstrucción y Fomento: el desarrollo económico de España (Madrid: Oficina de Coordinación y Programación Económica, 1962), 543.
} 
El régimen franquista debía afrontar no solo su línea de acción y continuidad, cada vez más exigua y con menos capacidad de atracción, sino también nuevas vías de transformación social a través del crecimiento industrial y del sector servicios. Era, por tanto, el momento de «iniciar una nueva etapa que permita colocar nuestra economía en la situación más amplia de libertad, de acuerdo con las obligaciones asumidas por España como miembro de la OECE».29

En esa nueva etapa de anhelo por cumplir con los estándares internacionales, la LGE tuvo un papel esencial, pues como apunta Escolano Benito «el tradicionalismo pedagógico era incompatible con la dinámica de industrialización que iniciaba el país, que exigía una nueva escuela, más acorde con las corrientes dominantes en los países en desarrollo».30 Además se pretendía dar una imagen en la que el impulso económico fuera unido al desarrollo político mediante medidas aperturistas, tales como la aprobación de la Ley de Convenios Colectivos (1958) o la Ley de Prensa e Imprenta (1966). ${ }^{31}$ Sin embargo, pronto comenzó a evidenciarse la crisis del régimen con las primeras críticas a este modelo desarrollista por parte de sectores de la oposición política, la reorganización del movimiento obrero, las desavenencias en el seno de la Iglesia y el creciente movimiento estudiantil. ${ }^{32}$ Se puede afirmar, por tanto, que no se estaba produciendo la trilogía de factores económicos, políticos y sociales necesarios para la modernización. España se adentraba así «en una fase de cierta anomia social, propia de una sociedad que aunque formalmente mantiene los patrones culturales del pasado, ya no se rige

29 Mediante el Decreto-Ley 10/1959, de 21 de julio de 1959, de ordenación económica, BOE núm. 174, de 22 de julio de 1959, se dejaba claramente establecida la legitimidad del Estado en todo lo concerniente a la vigilancia e impulso de la economía española.

30 Agustín Escolano Benito, «Discurso ideológico, modernización técnica y pedagógica crítica durante el franquismo», Historia de la educación: Revista interuniversitaria 8 (1989): 14.

31 La primera normativa (Ley de 24 de abril, sobre Convenio Colectivos Sindicales, BOE núm. 99, de 25 de abril de 1958) fue un mecanismo disuasorio ante el aumento huelguístico (1956-1958). Y la segunda medida (Ley 14/1966, de 18 de marzo, de Prensa e Imprenta, BOE núm. 67, de 19 de marzo de 1966) abría más espacios para la libertad de prensa, aunque el régimen seguía ejerciendo control sobre las publicaciones, siempre vigilada por el poder político.

$32 \mathrm{El}$ escenario en la educación no era más esperanzador. El régimen tenía que hacer frente a una ascendente ola de protestas en casi todas las universidades. La juventud constituyó una preocupación continuada desde el inicio de la década de los años sesenta, tal como se refleja en el «Informe sobre participación universitaria». AGA: Presidencia. Secretaría General del Movimiento "Informe sobre participación universitaria», c. 18.791. 
por ellos». ${ }^{33}$ Las continuas protestas se agudizaron a finales de los sesenta llevando al Estado de excepción decretado el 24 de enero de 1969 como medida urgente ante «las acciones minoritarias, pero sistemáticamente dirigidas a turbar la paz de España y su orden público». ${ }^{34}$ La nueva clase media y el proletariado industrial apelaban por una mayor libertad individual y por nuevos espacios políticos más críticos. El desfase entre política y sociedad eran más que evidentes, al igual que la agonía del régimen y la de su Caudillo.

Asimismo, desde la década de los setenta la presión internacional por la implantación de sistemas políticos democráticos iba siendo cada vez mayor. Por otra parte, los últimos años de la dictadura y los primeros de la transición se caracterizaron por la crisis económica mundial que representó el final de una etapa de prosperidad y el inicio de otra, caracterizada por la inflación y el estancamiento. España no logró detener el creciente desgaste político que unido a la situación económica avecinaba el fin de esa situación paradójica, el desfase entre política y sociedad. ${ }^{35}$ Para Álvaro Soto:

En España se produjo un proceso reformista donde primó, hasta las elecciones de 1977, la presión "desde abajo". A partir de dicho momento, al poder contar con representantes legítimos las políticas de presión fueron remplazadas por acuerdos de elites. Estos últimos pactos, supusieron avances muy significativos en el campo político y económico, aunque tuvieron un importante coste para los actores sociales que vieron como perdían el apoyo de la población. ${ }^{36}$

Esa presión «desde abajo» encauzó el camino de lo que más tarde sería la reforma política de los primeros años de la transición. Ahora bien, ¿qué reforma educativa era posible en este contexto?

\footnotetext{
33 Félix Ortega, El mito de la modernización. Las paradojas del cambio social (Barcelona: Anthropos, 1994), 30.

34 Decreto-Ley 24/1969, de enero de 1969, por el que se declara el estado de excepción en todo el territorio español, BOE núm. 22, de 25 de enero de 1969. Asimismo, durante los tres meses en los que quedó declarado el estado de excepción se suprimieron algunos artículos del Fuero de los Españoles, en concreto, los artículos 12, 14, 15, 16 y 18.

35 Gonzalo Fernández de la Mora, El crepúsculo de las ideologías (Madrid: Espasa Calpe, 1986), 181.

36 Álvaro Soto Carmona, «Los pactos en las transiciones democráticas. España: 1975-1982», APORTES 93, no. 1 (2017): 242.
} 


\section{LA LGE. HACIA UNA «REVOLUCIÓN PACÍFICA» EN EL CONTEXTO DE LA DICTADURA Y LOS INICIOS DE LA TRANSICIÓN (1970-1978)}

Desde el inicio de la dictadura, la educación fue una de las principales preocupaciones del régimen, lo que tuvo un reflejo muy destacado en su política educativa. Con la entrada de los tecnócratas en el seno de la élite franquista, se inicia una etapa marcada por la despolitización y el control de las protestas sociales -movimiento estudiantil, huelgas obreras, etc. $-^{37}$ España debía adaptarse a las nuevas exigencias del capitalismo occidental sin que ello implicara la transición hacia una democracia homologable al resto de Europa, sino la necesidad de mantener un sistema político que lentamente iba resquebrajándose ante la creciente conflictividad y disentimiento social. ${ }^{38}$

El régimen era consciente de que para neutralizar y alcanzar el control social debía adoptar un cariz camaleónico y mutante que se adecuara tanto a las condiciones externas, requeridas a nivel internacional, como internas, con la cuestión universitaria. En este sentido, como recuerda uno de sus principales artífices, Ricardo Díez Hochleitner, la aprobación de la LGE fue «decidida y emprendida a causa de la conjunción de una serie de factores inmediatos, de los cuales el más evidente era, sin duda, la crisis de orden académico y de orden público en que se debatían las Universidades españolas». ${ }^{39}$ A ello se unía la carencia de

\footnotetext{
37 La nueva cúpula del Estado franquista estuvo conformada por la élite tecnocrática, destacando Jesús Rubio García-Mina, Laureano López Rodó, Torcuato Fernández Miranda, Manuel Lora Tamayo, Manuel Fraga Iribarne, José María Albareda, etc., y por consultores internacionales de la UNESCO, tales como Ricardo Díez Hochleitner, Friedrich Edding y Herbert S. Parnes. En abril de 1968 el entonces ministro de Educación, Manuel Lora Tamayo, presentó su dimisión ante su disconformidad con la gestión de las revueltas universitarias, siendo sustituido por el catedrático de Derecho Administrativo, José Luis Villar Palasí. Sara Morgenstern de Finkel, «Transición política, práctica educativa y formación del profesorado», Revista de Educación, 284 (1987): 77-99.

38 Sobre esta cuestión han insistido, entre otros: Carmen Molinero e Pere Ysàs, La anatomía del franquismo. De la supervivencia a la agonía, 1945-1977 (Barcelona: Crítica, 2008). Diego Sevilla Moreno, «La difícil traslación a una política de gobierno de un acuerdo constitucional forzado. La Unión de Centro Democrático y su malograda Ley Orgánica del Estatuto de Centros Escolares (LOECE) de 1980», Historia y Memoria de la Educación, 3 (2016): 45-70. Alejandro Mayordomo Pérez, «La transición a la democracia: educación y desarrollo político», Historia de la Educación: Revista Interuniversitaria, 21 (2002): 19-47: 24.
}

39 Ricardo Díez Hochleitner, Joaquín Tena Artigas y Marcelino García Cuerpo, La reforma educativa española y la educación permanente (París: UNESCO, 1977), 13. El citado Díez Hochleitner tuvo un papel destacado en las ideas asociadas a la reforma del sistema educativo español y en la búsqueda de los contactos internacionales para su financiación. Desde su incorporación al Ministerio de Educación y Ciencia de Villar Palasí, ocupando, primero, la Secretario General Técnica (mayo de 1968) 
recursos en el campo educativo y científico que canalizaran las demandas de los sectores implicados, así como de una mayor participación social. El desgaste del régimen y la preocupación por lo que se denominó "problema de la sucesión» ${ }^{40}$ marcaron las señas de identidad de esta etapa. Y será desde esta nueva concepción educativa en la que se contextualice la LGE como revulsivo para modernizar el país en consonancia con las teorías del capital humano. Precisamente, desde la década de los setenta, el Ministerio de Educación y Ciencia (MEC) venía desarrollando diversos proyectos educativos relacionados con propuestas ya planteadas por la UNESCO y, sobre todo, teniendo como referente los Planes de Desarrollo Económico y Social. ${ }^{41}$

En efecto, era necesario modernizar el sistema educativo para alcanzar los estándares de crecimiento económico previstos para la década de los setenta siendo clave la transformación del Ministerio de Educación Nacional (1938-1966) por el MEC. ${ }^{42}$ Se iniciaba así lo que sus promotores denominaron "una revolución pacífica y silenciosa» en materia educativa. ${ }^{43} \mathrm{Y}$, con ello, una mejora de la eficiencia y la calidad del sistema

y, al poco tiempo, la Subsecretaría (noviembre de 1969 a mayo de 1972), diseñó el proyecto de reforma educativa global, y dirigió la redacción del Libro Blanco y del anteproyecto de la LGE. Previamente había ejercido el cargo de director del Departamento de Planificación y Financiación de la UNESCO, y había participado en la elaboración de diversos informes sobre España en esta materia. Ricardo Díez Hochleitner, «La reforma educativa de 1970. Su pequeña historia», en Simposium Internacional sobre Educación e Ilustración (Madrid: MEC, 1988), 477-498.

40 Antonio Viñao Frago, Escuela para todos. Educación y modernidad en la España del siglo XX (Madrid: Marcial Pons, 2004). Pamela O'Malley, «Turning point: the 1970 Education Act», in Education Reform in Democratic Spain, International Developments in School Reform, ed. Oliver Boyd-Barret (New York: Routledge, 1995), 25-31.

41 Medidas que se materializaron en la ampliación del período de escolaridad obligatoria hasta los catorce años de edad (Ley 27/1964, de 29 de abril, sobre ampliación del período de escolaridad obligatoria hasta los catorce años, BOE núm. 107, de 4 de mayo de 1964); el aumento de puestos escolares para la enseñanza primaria y media; la implantación de cuestionarios nacionales de enseñanza primaria (Orden de 8 de julio de 1965 por la que se aprueban los cuestionarios que han de regir todas las actividades didácticas en las Escuelas Primarias, BOE núm. 229, de 24 de septiembre de 1965); etc. En esta línea, destaca el informe realizado a comienzos de 1966 por el Secretario General Técnico del Ministerio de Educación y Ciencia, Antonio Tena Artigas, sobre la situación de la educación en España. Antonio Tena Artigas, «La Educación y el primer Plan de Desarrollo», Revista de Educación 180 (1966): 26-31.

42 «El Ministro de Educación y Ciencia explica la política del nuevo Ministerio», Revista de Educación, 178 (1966): 90.

43 Preámbulo de la Ley 14/1970, de 4 de agosto, General de Educación y Financiamiento de la Reforma Educativa (LGE), BOE, n. ${ }^{\circ} 187$, de 6 de agosto de 1970. La reforma consta de 146 artículos, 4 disposiciones finales, 16 transitorias y 7 adicionales. 
educativo que le precedía, la denominada «Ley Moyano» de 1857, que respondía tanto a nivel jurídico como teórico a esquemas liberales y decimonónicos. ${ }^{44}$ Con esta ley integral y homogénea se dejaban atrás las sucesivas reformas sectoriales acumuladas hasta entonces contando «como pocas del clamoroso deseo popular de dotar a nuestro país de un sistema educativo más justo, más eficaz, más acorde con las aspiraciones y con el ritmo dinámico y creador de la España actual». Se trataba, como asimismo se recoge en el preámbulo de la reforma, de:

Hacer partícipe de la educación a toda la población española [...], completar la educación general con una preparación profesional que capacite para la incorporación fecunda del individuo a la vida del trabajo, ofrecer a todos la igualdad de oportunidades educativas, sin más limitaciones que la de la capacidad para el estudio; establecer un sistema educativo que se caracterice por su unidad, flexibilidad e interrelaciones, al tiempo que se facilita una amplia gama de posibilidades de educación permanente y una estrecha relación con las necesidades que plantea la dinámica de la evolución económica y social del país. ${ }^{45}$

Una lectura a cierta distancia nos permite entrever lo paradójico de la ley en cuanto que un régimen político tan estático y receloso como el franquismo quisiera acometer una reforma en uno de los ámbitos, el educativo, más perseguidos y desmantelados por la dictadura. ${ }^{46} \mathrm{Y}$ además que se hiciera a partir de la crítica radical del aparato escolar. Lo que implicaba reconocer implícitamente el fracaso de la educación autoritaria instaurada por el propio régimen. Para ello, se tomó como base el denominado «Libro Blanco» (1969), elaborado por la Secretaria General Técnica del MEC y presentado a la Comisión de Educación de las Cortes Españolas y al Consejo Nacional del Movimiento ${ }^{47}$. El interés de este documento técnico radicó precisamente en el profundo análisis

\footnotetext{
44 Puelles Benítez, «Tecnocracia y política en la reforma educativa de 1970», 18.

45 LGE, Preámbulo.

46 Félix Ortega, «La ideología de la reforma educativa de 1970», Revista de Educación n. ${ }^{\circ}$ ext. «La Ley General de Educación veinte años después» (1992): 35.
}

$47 \mathrm{Y}$ aprobado en pleno estado de excepción. Su elaboración corrió a cargo de un equipo interdisciplinar de expertos y técnicos especialistas que se encargaron tanto del borrador como de la propia ley. El equipo estuvo dirigido por José Blat Gimeno, vicesecretario general técnico del MEC. Amparo Blat Gimeno, "El Llibre Blanc i la Llei General d'Educació de 1970 segons Blat Gimeno", 
de la situación de la educación en España, junto a un conjunto de propuestas para su reforma integral. Las principales carencias del sistema educativo hacían referencia a los siguientes aspectos. ${ }^{48}$ Por un lado, era evidente la discriminación en el acceso a la educación, cuya estructura apenas había sido modificada durante más de un siglo, existiendo dos niveles diferenciados de educación primaria tal y como se denuncia en el documento:

En la base de la estructura del sistema educativo español se observa una anomalía muy grave: la existencia de dos niveles diferentes en educación primaria. Para los niños que ingresan en centros de Enseñanza Media, la duración de la escolaridad primaria llega solamente hasta los diez años de edad; para los demás, hasta los catorce. ${ }^{49}$

Esto provocaba que la propia base del sistema educativo fuera discriminatorio por la existencia de dos niveles de educación. Esta dualidad, determinada según un criterio socioeconómico de clase, originaba que las familias con más recursos enviaran a sus hijos a centros privados de enseñanza primaria o media para posteriormente acceder a la universidad. Mientras que los hijos de las familias menos pudientes cursaran la enseñanza primaria en centros públicos teniendo escasas posibilidades de proseguir estudios universitarios, pues su proyección formativa se agotaba en la formación profesional o como mucho en el acceso a las Universidades Laborales destinadas a la clase trabajadora. Por otro lado, el paso a la enseñanza media a la edad de diez años se consideraba perjudicial y "particularmente brusco», ya que representaba una edad temprana en la evolución psicológica y pedagógica del estudiante. Era, por lo tanto, un sistema elitista y selectivo desde el primer nivel educativo hasta la Universidad. Los supuestos logros alcanzados en los treinta años anteriores de dictadura aparecían ahora como graves deficiencias, pues:

\footnotetext{
Educació i Història 36 (2020): 161-175. MEC, La educación en España. Bases para una política educativa (Madrid: MEC, 1969).

48 José Luis Fernández Cantos y Joaquín G. Carrasco, Ley General de Educación. Espíritu y realidad de la reforma educativa española (Salamanca: Ediciones Sígueme, 1971).

49 MEC, La educación en España. Bases para una política educativa, 17.
} 
Los fines educativos se concebían de manera muy distinta en aquella época y reflejaban un estilo clasista opuesto a la aspiración, hoy generalizada de democratizar la enseñanza. Se trataba de atender a las necesidades de una sociedad diferente de la actual Hacer partícipe de la educación a toda la población española, dos millones y medio de jornaleros del campo y doscientos sesenta mil «pobres de solemnidad», con una estructura socioeconómica preindustrial en la que apenas apuntaban algunos intentos aislados de industrialización. ${ }^{50}$

En esta nueva estructura del sistema educativo, el período de Educación General Básica se estableció como único, obligatorio y gratuito basado en el principio de igualdad de oportunidades. ${ }^{51}$ La enseñanza media a través del Bachillerato Unificado y Polivalente ofertaba un amplio abanico de posibilidades práctico-profesionales orientadas a potenciar las aptitudes de los estudiantes y evitar el carácter excesivamente teórico y academicista del anterior sistema. Además, en el artículo 2 se anunciaba la extensión de la gratuidad de la enseñanza al bachillerato, una vez conseguidos los fines de la enseñanza básica. Y se introducía en las enseñanzas universitarias distintos ciclos e instituciones que permitieran una mayor flexibilidad y posibilidades de especialización profesional. Se trataba, según se recoge en el Preámbulo de la LGE, de «construir un sistema educativo permanente no concebido como criba selectiva de los alumnos, sino capaz de desarrollar hasta el máximo la capacidad de todos y cada uno de los españoles».52

Para ello, la nueva orientación política apostó por superar el viejo modelo del nacionalcatolicismo introduciendo uno más intervencionista y liberal. Esto implicó, en cierto modo, admitir lo positivo del pasado republicano, tan denostado y perseguido por el propio régimen. El

\footnotetext{
50 LGE, preámbulo.

51 La aprobación de la Constitución Española de 1978 (BOE, n..$^{\circ}$ 311, de 29/12/1978) implicaría reconocer el derecho a la educación (artículo 27). En principio, este derecho recaía en la educación institucionalizada. Sin embargo, en el punto 4 del mismo artículo, este derecho -que es un deber para los progenitores- se restringe a la enseñanza básica, de los 6 a los 14 años, siendo además obligatoria y gratuita únicamente en este nivel educativo. Cfr. Diego Sevilla Moreno, «La difícil traslación a una política de gobierno de un acuerdo constitucional forzado. La Unión de Centro Democrático y su malograda Ley Orgánica del Estatuto de Centros Escolares (LOECE) de 1980», Historia y Memoria de la Educación, 3 (2016): 50.
}

52 LGE, preámbulo. 
objetivo era lograr una "auténtica convivencia política» por medio de la «Socialización de la enseñanza».53 En este sentido, resultan reveladoras las palabras de Villar Palasí el día que el dictamen de la reforma fue sometida a la aprobación del Pleno de la Cámara, identificándola como una «Ley de paz. Una Ley llamada a integrar a los españoles desde la base, desde la escuela [...] Se trata de borrar definitivamente los trazos que aún persisten de desigualdad, discriminación e injusticia en el panorama de la formación y cultura de nuestro pueblo». ${ }^{54}$ En efecto, el agotamiento del régimen, cada vez más acusado, vislumbraba una apertura de sus estructuras internas impregnado por un discurso político que viraba entre la ruptura y la alianza, y avecinaba la llegada de la transición a la democracia parlamentaria en España. Serán, pues, estas las claves en las que se contextualice la LGE; una ley que por las circunstancias políticas e históricas en las que se gestó no lograría tener el impacto deseado pasando del reconocimiento a la negación.

\section{DEL RECONOCIMIENTO A LA NEGACIÓN DE LA LGE. POSIBLES RAZONES}

En el mes de agosto de este año se ha cumplido medio siglo de la aprobación de la primera ley educativa integral del siglo XX. Si bien es cierto que hoy podemos valorarla críticamente, hay que reconocer que tuvo aspectos novedosos, dentro de los márgenes y limitaciones de una dictadura, siendo decisiva desde la perspectiva actual. Asimismo, si tenemos en cuenta el tiempo en la que estuvo vigente, hasta ya entrada la democracia, parecería que estamos ante un éxito de estabilidad educativa. Sin embargo, con el paso del tiempo el balance es agridulce. Del reconocimiento que siguió al espíritu de la ley, se pasó a poner en cuestión la reforma educativa mostrándose un profundo desencanto y negación de sus logros. A la vista de tanto desencanto veamos pues algunas de las posibles razones.

En una primera aproximación, no sería aventurado afirmar que pocas leyes han suscitado tantas expectativas y controversias como la

\footnotetext{
53 Joaquín Ruíz-Giménez, «Educación y socialización», Cuadernos para el Diálogo 79 (1970): 18.

54 Boletín Oficial de las Cortes. Diario de Sesiones del Pleno, n. 2 (28 de julio de 1970). Se aprobó con un solo voto en contra.
} 
reforma de $1970 .{ }^{55}$ Su aprobación constituyó un verdadero revulsivo educativo en la España franquista y el "primer ensayo de la "transición" del régimen en su intento de supervivencia». ${ }^{56} \mathrm{Si}$ nos atenemos estrictamente al texto de la reforma, por primera vez se asentaban las bases de una serie de principios educativos que apostaron por europeizar y adaptar el sistema escolar a las necesidades de una sociedad en proceso de expansión. Entre sus principales aportaciones destacarían: el derecho a la educación, la concepción de la educación como una tarea inacabada; el concepto de flexibilidad y unidad en el sistema educativo; la preocupación por la calidad y rendimiento del sistema educativo; la educación permanente orientada hacia los aspectos formativos para aprender por sí mismo; la creación de servicios de orientación educativa y profesional; la introducción de nuevos métodos y técnicas de enseñanza; el perfeccionamiento del profesorado; o la inclusión de métodos didácticos innovadores que se adecuaran a la evolución psicobiológica del alumnado potenciando su creatividad, el trabajo en equipo y la cooperación. Además se dispusieron normas relativas a la promoción de edificios e instalaciones educativas, el calendario escolar único, la evaluación del rendimiento escolar y la función de planificación y programación estatal. ${ }^{57}$ Es decir, una serie de declaraciones y principios innovadores que

55 El alto índice de expectación que había suscitado la reforma se refleja, por ejemplo, en el Libro Blanco que fue presentado el 12 de febrero de 1969 y apenas dos semanas después ya estaba agotada la primera edición.

56 Félix Ortega, «La ideología de la reforma educativa de 1970», 31.

57 LGE, disposición adicional séptima. En el Diario de Sesiones de Comisiones del Boletín Oficial de las Cortes Españolas se hace referencia precisamente a esa metodología activa de la educación propuesta en la ley. Así lo destacaba el subsecretario del Ministerio de Educación y Ciencia al mencionar el espíritu de la reforma: «estamos cambiando la actitud que los procesos educativos tradicionalmente han tenido, centrados demasiado quizá en el sujeto de la educación sometiéndolo a examen, a pruebas, a dificultades, en el deseo de ayudarle a promocionarse, a formarse e instruirse». Se trataba de un nuevo planteamiento del sistema educativo en el que se apuesta por nuevas técnicas de aprendizaje. Esta idea venía avalada por los propios organismos internacionales. La revista activista Les Cahiers Pédagogiques, en su monográfico «Examen des examens», se hacía eco de la Conferencia de Ministros Europeos de Educación, celebrada en Estrasburgo en 1967, en la que se había criticado la rigidez de la metodología tradicional empleada en los sistemas educativos, apostando por un sistema de pruebas en lugar de exámenes: «[...] la imposición de frecuentes exámenes al estilo tradicional, somete a los alumnos a pruebas que no son siempre objetivas y comparables [...] y sustituye en los jóvenes la mala asimilación memorística de materias demasiado extensas. El control del conocimiento debería hacerse con técnicas nuevas». Les Cahiers Pédagogiques 92 (1970): 7. Asimismo, en el Libro Blanco se denunciaba que «las pruebas establecidas en determinados momentos del proceso educativo producen estrangulamientos importantes. [...] En resumen: de cada 100 alumnos que iniciaron la enseñanza primaria en 1951, llegaron a ingresar 27 en Enseñanza Media; aprobaron la revalidad del Bachiller Elemental 18 y 10 el Bachillerato Superior, aprobaron el Preuniversitario 
seguramente hoy día serían asumibles en cualquier normativa educativa, pues predominaban aspectos novedosos y modernos sobre los puramente técnicos.

Ahora bien, no podemos olvidar que se trataba de una reforma enmarcada en un contexto político de crisis, tal como hemos constatado en estas páginas, con un importante componente ideológico, aparte del aspecto científico, lo que que producía un efecto contradictorio por su carácter ambivalente. Como señala Puelles Benítez, fue una reforma híbrida en cuanto que era un texto on claras referencias a los principios ideológicos del régimen, a la vez que se apoyaba en una serie de aspectos innovadores que se venían defendiendo en las reformas educativas europeas. Es decir, se pretendía adecuar un sistema educativo desfasado a las exigencias de los planes de desarrollo y de una economía cada vez más industrializada que requería mano de obra cualificada, especialmente en el sector terciario. Como se indica en el preámbulo de la ley era necesario establecer «un sistema educativo eficaz» entendiéndolo como «la más noble y productiva de las inversiones» en aras de implantar «una estrecha relación con las necesidades que plantea la dinámica de la evolución económica y social del país». Asimismo, estos tintes liberales implicaban que el franquismo reconocía en parte el fracaso de la educación autoritaria y elitista de los últimos treinta años. Y se alejaba así de las líneas básicas del nacionalcatolicismo adoptando una nueva estructura educativa más acorde a las expectativas de las teorías del capital humano en cuanto a la correlación entre educación, crecimiento económico y desarrollo social. ${ }^{58}$ En la línea del documento de la OCDE, la educación era concebida como «un bien de consumo desde el punto de vista del individuo, independientemente de su consideración como factor de crecimiento». 59

cinco y culminaron estudios universitarios tres alumnos en 1967». MEC, La educación en España. Bases para una política educativa, 17.

58 A partir de la década de los sesenta se introducen en España las teorías de los economistas del Capital Humano siendo numerosos los trabajos e informes que relacionan, dentro del marco neoclásico, la educación con el desarrollo económico concibiéndose como una inversión. José Luis Romero y Amando de Miguel, El Capital Humano. Ideas para una planificación social de la enseñanza en España (Madrid: Conf. Esp. CC. de Ahorros, 1969).

59 MEN-OCDE, Las necesidades de educación y el desarrollo económico-social de España (Madrid: MEN -OCDE, 1963), 14. 
No obstante, la apuesta por estos elementos predominantemente innovadores no implicó que el dirigismo autoritario desapareciera. Tal como afirma Morgenstern «la reforma fue una parte importante de un proyecto político orientado a la perpetuación de la misma estructura del poder de clase después de la dictadura». ${ }^{60}$ La continuidad con la política educativa anterior se aprecia, por ejemplo, en el peso que siguió teniendo la moral católica y en las reticencias a la coeducación. ${ }^{61}$ Así en el artículo primero de la ley se defendía una formación humana integral inspirada en «el concepto cristiano de la vida y la tradición y culturas patrias. [...] todo ello de conformidad con lo establecido en los Principios del Movimiento Nacional y demás Leyes Fundamentales del Reino». Quedaba claro, pues, que la enseñanza religiosa formaba parte esencial de la educación mostrando fidelidad a los ideales cristianos y patrióticos. Asimismo, en el artículo quinto referente a la «libertad de enseñanza» se partía de los planteamientos eclesiásticos y de la situación privilegiada de la enseñanza privada cumpliendo con lo estipulado en los Principios del Movimiento y en el Fuero de los Españoles en defensa de la "Ley de Dios».62 Es más, las Leyes Fundamentales prescribían al Estado respetar los derechos de la Iglesia. Es decir, mantener la educación privada no universitaria teniendo la opción de ofertar puestos escolares gratuitos de enseñanza obligatoria a cambio de soporte económico. ${ }^{63}$ Hay una mención explícita a que «ese espíritu de convivencia respondiera justamente a todas las declaraciones de los Principios

\footnotetext{
60 Sara Morgenstern de Finkel, «The scenario of the Spanish Educational Reform», en Understanding Educational Reform in global context. Economy, ideology and the State, ed. Mark Ginsburg (Nueva York: Garland Publishing, 1991), 157.

61 LGE, artículo 18.

62 Discurso de Villegas Girón. Sesión plenaria celebrada el 2 de abril de 1970. Boletín Oficial de las Cortes Españolas, n. ${ }^{\circ}$ 1094, 37.

63 En relación con las consideraciones precedentes, conviene recordar que durante el franquismo, la educación de la población, especialmente de la juventud, fue un instrumento con fines ideológicos y de control social para aplacar a los opositores y procurar la continuidad de la dictadura en las nuevas generaciones. Por lo que, desde un primer momento, se convirtió en uno de los principales dispositivos del Estado en la formación de valores, ideología y subjetividades de los españoles. En esta línea, las organizaciones juveniles de la Falange (Frente de Juventudes y Sección Femenina del Movimiento) y de la Iglesia (Acción Católica) sirvieron de mecanismos de iniciación y socialización de las generaciones más jóvenes. El artículo quinto del Fuero de los Españoles hacía referencia al individuo protegido por el Estado, señalándose que: «todos los españoles tienen derecho a recibir educación e instrucción y el deber de adquirirlas, bien en el seno de su familia o en centros privados o públicos, a su libre elección. Por lo que el Estado velará para que ningún talento se malogre por falta de medios económicos». BOE, núm. 199, de 18 de julio de 1945.
} 
Fundamentales, y demás Leyes Fundamentales de modo absoluto, sin precisar artículo por artículo. En todas ellas hay referencias a la familia, a la educación, a la religión, al hombre, a la iniciativa privada, al trabajo y a los fines de la Estado».64 En cuanto a la coeducación se diferenciaba entre la coenseñanza y la coeducación, considerándose que no hacía falta que una ley hiciera referencia explícita a este tipo de educación porque «ni siquiera se trata de un tema tenga perfecta identidad. La afectividad se informa y se educa, [...] darle una entidad que no tiene, puede llevar a una fijación y polarización que altere el lugar que le corresponde dentro de la jerarquía de los valores personales». ${ }^{65}$

El terreno estaba ya abonado para un nuevo escenario hacia la transición democrática, aunque no carente de tensiones políticas e ideológicas, ya que «por debajo de la unificación política y de la afinidad ideológica y emocional existente entre los diversos grupos políticos, hubo siempre dentro del franquismo un cierto pluralismo y disensiones políticas de distinta intensidad».66 El propio Villar Palasí, en su discurso sobre la reforma en el Pleno de las Cortes al dirigirse a los procuradores en Cortes, denunció la dificultad que supuso la promulgación de la ley: «O ¿es que no sabemos todos, vosotros y yo, qué grupos de presión quisieron negar a esta ley el pan y la sal del futuro y por qué vericuetos se intentó llegar a ello? La Historia, con mayúscula, lo recogerá».67 En todo caso, tras meses de acalorado debate por parte de los grupos de presión en el marco de un pluralismo restringido, fue posible su aprobación, en sesión plenaria de 28 de julio de 1970. Pero, una vez puesta en marcha, afloraron los primeros síntomas de desencanto por parte de determinados colectivos de la sociedad peor situados en la enseñanza estatal (profesorado no numerario y magisterio) y, consecuentemente, las primeras críticas a la política educativa del Estado. ${ }^{68}$ En consecuencia, desde su gestación se produjeron en diferentes momentos los primeros enfrentamientos

\footnotetext{
64 Diario de Sesiones. Villegas Girón Sesión 2 de abril de 1970.

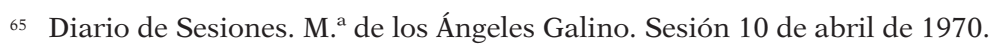

66 Raymond Carr y Juan Pablo Fusi, España, de la dictadura a la democracia (Barcelona: Planeta, 1979), 221.

67 Discurso del Ministro de Educación y Ciencia Villar Palasí. Diario de Sesiones. Boletín Oficial de las Cortes Españolas, n. ${ }^{\circ} 2,1970$.

68 Marta Jiménez Jaén, La Ley General de Educación y el movimiento de enseñantes. Un análisis sociológico (La Laguna: Universidad de La Laguna, 2005).
} 
y polémicas por parte de sectores del Movimiento y de la oposición ideológica al régimen, cada vez más numerosa. Por lo que no es de extrañar que la reforma no sobreviviera al proceso de aplicación. Algunas veces paralizándose y otras desnaturalizándose su esencia. Con el paso de los años las limitaciones fueran más que evidentes al chocar con el predominio de la adhesión a los valores democráticos.

Por otro lado, más allá de estos aspectos, estaban presentes las expectativas generadas por la reforma centrada en las funciones, objetivos y fines planteados por los legisladores. En cualquier caso, en la línea ya planteada por Althusser, la reforma de 1970 quedaría por debajo de las expectativas generadas provocando incluso efectos nulos o contrarios a los proyectados. ${ }^{69}$ Esto es así, en parte, por el componente de idealismo que se inyecta en las mismas, y que Martín Criado lo articula en torno a tres grandes ejes que van más allá del simple deseo de cambiar o transformar una realidad. ${ }^{70}$ Unas expectativas que Cabrera Montoya denomina «de desplazamientos» al plantearse unas exigencias que llegan incluso a ser incumplibles y contradictorias, pues parten de una imagen idealista de la educación y no son abordadas en los ámbitos específicos donde se producen esos problemas. En el caso de España, se le exigía al sistema educativo que resolviera una serie de problemas sociales y económicos tanto de naturaleza coyuntural como estructural que escapaban de su propia competencia y que invitaban a que de antemano se percibiera utópica. ${ }^{71}$ En efecto, como recordaba Villar Palasí se trataba de ofertar una «educación general básica, sí, igual y gratuita para todos, para ricos y para pobres, para los hijos de empresarios y obreros, como

\footnotetext{
69 Althusser en su teoría general de la ideología matiza que ésta no tiene historia, sino que la atraviesa al igual que hace el inconsciente. Louis Althusser, Ideología y aparatos ideológicos del Estado. Freud y Lacan (Nueva Visión: Buenos Aires, 1988), 22.

70 El primero, es partir de la retórica que las sociedades las conforman individuos, en lugar de relaciones objetivas entre posiciones; el segundo, es un presupuesto idealista y voluntarista basado en identificar la socialización escolar, entendida como la asimilación de unas normas y valores, como la decisiva en el comportamiento del individuo, eludiendo el resto de aprendizajes externos a la escuela; y el tercero, es obviar que los sistemas educativos responden a sistemas burocráticos que representan luchas de poder orientadas a imponer de manera imperativa prácticas educativas ajustadas a un marco axiológico. Enrique Martín Criado, «El idealismo como programa y como método de las reformas escolares», El nudo de la Red 3, no. 4 (2004): 18-32.
}

71 Blas Cabrera Montoya, «La obediencia de las reformas educativas a las políticas educativas internacionales. Breve historia de cómo se hace camino desde la Ley Orgánica General del Sistema Educativo (LOGSE) de 1990 a la Ley Orgánica de Mejora de la Calidad Educativa (LOMCE) de 2013», Historia y Memoria de la Educación 3 (2016): 174. 
deber y derecho fundamental de los españoles». ${ }^{72}$ Lógicamente, para llevar a la práctica estos ambiciosos planteamientos se requería de instituciones docentes, recursos didácticos, profesorado, etc., máxime cuando la enseñanza básica y la formación profesional de primer grado pasaban a ser obligatorias y gratuitas. Junto a esta desactivación de los mecanismos financieros necesarios para la implantación y desarrollo de la reforma, se sumaron otras razones como fue la falta de legitimidad política y social, la confrontación entre los sectores del Movimiento y el rechazo por la parte más progresista de la sociedad. Para Díez Hotchleiner «faltó voluntad política para una generosa visión de futuro y consiguiente financiación. Esto contribuyó a que muchas cosas se quedaran en el camino». ${ }^{73}$ En la exposición de motivos de la LGE se preveía un período de diez años para su implantación con el propósito de obtener el mayor rendimiento del sistema nacional y de los recursos invertidos. Además se trataba de una ley emanada de un régimen dictatorial, por lo que dada las propias condiciones ideológicas y políticas en las que se elaboró, no fue posible contar con las propuestas de los movimientos pedagógicos de carácter progresista ni con un debate políticamente hablando. ${ }^{74}$ Fue, por tanto, «una buena reforma "desde arriba" al más puro estilo regeneracionista», anota Vega Gil. ${ }^{75}$

Es evidente que la LGE no llegó a cumplir las expectativas marcadas en el papel. Esto hizo que no tuviera el impacto esperado, a pesar de sus innegables consecuencias positivas a nivel educativo, social y económico, siendo de algún modo denostada. Así si en una primera etapa fue sinónimo de pacificación de un conflicto social, ideológico y político que, en buena medida, pretendía solventarse a través de la educación,

\footnotetext{
72 Discurso de Villar Palasí ante la Comisión de Educación de las Cortes celebrado el 1 abril de 1970.

73 Ricardo Díez Hotchleitner, «La reforma educativa de la Ley General de Educación de 1970. Datos para una crónica», Revista de Educación n. ${ }^{\circ}$ ext. «La Ley General de Educación veinte años después» (1992): 278. Los costes financieros de la LGE se incorporaron por anualidades a los Presupuestos Generales del Estado. En la Disposición Adicional segunda de la LGE se indicaban unas cifras orientativas sobre presupuestos de los gastos corrientes del MEC para llevar a cabo la reforma.

74 Informe que eleva al Gobierno la Comisión evaluadora de la Ley General de Educación y Financiamiento de la Reforma Educativa en cumplimiento del Decreto 186/76 de 6 de febrero, Madrid, 1976. Sobre la educación en la transición política a la democracia destacar el análisis de Alejandro Mayordomo Pérez, «La transición a la democracia: educación y desarrollo político». Historia de la Educación: Revista Interuniversitaria 21 (2002): 19-47.
}

75 Leoncio Vega Gil, « La reforma educativa en España (1970-1990)», Educar em revista 13 (1997): 111. 
con el transcurso del tiempo las deficiencias y lastres de la reforma fueron más que evidentes. Por un lado, desde un punto de vista teórico, se trataba de una reforma ambiciosa que abarcaba todas las dimensiones del sistema estructural, curricular, organizativo y administrativo, aportando importantes logros, tales como la edificación de un tipo de escuela más integradora -el propio José Blat Gimeno, técnico proveniente de la UNESCO y principal responsable del Libro Blanco, admitía haberse inspirado en el modelo británico de la «comprehensive school»-76; la integración de la formación del profesorado en las Universidades; etc. Pero, por otro lado, por muy innovadora que fuese respondió a criterios ideológicos de la élite tecnocrática franquista, al margen de cualquier debate o consenso con los sectores implicados de la sociedad civil (comunidad educativa, fuerzas sociales interesadas en la educación, etc.). Para gran parte del colectivo docente la reforma había sido impuesta sin consenso ni debate en cuanto a su diseño, por lo que «continuaron con su inercia en la práctica de un habitus profesional». ${ }^{77}$

Todo esto evidenciaba las contradicciones del propio régimen cuando desde un gobierno autoritario se cuestionaba todo el sistema educativo y se pretendía homologarlo a nivel europeo. Lo que supuso un enfrentamiento entre los distintos sectores desde los más integristas del régimen pasando por la parte más conservadora de la Iglesia hasta los más progresistas, pues defendían posturas dispares y en ocasiones antagónicas. ${ }^{78}$ Pues más allá del nivel político y prescriptivo no debemos obviar el contexto ideológico en el que se desarrolló la reforma así como el papel que ejercieron los movimientos pedagógicos. Llegó un momento en el que la maquinaria articulada por el propio régimen supuso un obstáculo en ese proceso de desideologización de la administración pública y de la sociedad en general; y, la modernización y el desarrollismo dejaron de ser los principios legitimadores del franquismo. A pesar de

\footnotetext{
76 Pamela O’Malley, La educación en la España de Franco (Madrid: Gens, 2008), 105.

77 Miguel Beas Miranda, «Formación del magisterio y reformas educativas en España: 1960-1970», Revista de currículum y Formación del profesorado 14, no. 1 (2010): 411. Sobre la formación incial y permanente del profesorado destacar de manera sucinta, la importancia de los Institutos de Ciencias de la Educación (ICEs) tanto en los aspectos formativos a nivel pedagógico como en el asesoramiento técnico en los problemas educativos.

78 Pamela O’Malley, «La Alternativa», Revista de Educación n. ${ }^{\circ}$ ext. «La Ley General de Educación veinte años después» (1992): 325-337. Estos aspectos son evidenciados en algunos de los artículos de la reforma que tras los debates de la Comisión sufrieron modificiaciones.
} 
defenderse por parte del régimen que el crecimiento económico haría posible «el progreso sin trastocar el orden político» la legitimidad del orden social partía no desde las instancias de la Iglesia o del Movimiento, sino desde la preeminencia de los resultados escolares. ${ }^{79}$ Pues bien, el cambio en materia de política educativa de la mano de los tecnócratas que representaban el sector más aperturista del régimen se basó en una concepción desarrollista que pretendía alejarse del riguroso control ideológico e introducir cambios fundamentales en el aparato escolar español. Sin embargo, los problemas de financiación, la escasez de recursos materiales y humanos necesarios para una aplicación efectiva de la reforma, así como la precipitación en su aplicación, sin tiempo ni ensayos experimentales, abocaron a la ley hacia el fracaso. Además tuvo la limitación de la existencia de una administración centralizada, lo que implicaba uniformidad y descontextualización de las demandas educativas de cada territorio. ${ }^{80}$ Han transcurrido cincuenta años de la aprobación de la LGE y resulta, al menos curioso, que a pesar del recelo que despertó entre quienes se opusieron a su financiación, ha estado en vigor en los primeros diez años de democracia, hasta la aprobación de la LODE (1985), y durante veinte años, hasta la reordenación del sistema educativo (LOGSE, 1990). No cabe duda que representó un antecedente de la política educativa democrática que años más tarde, tras haber atravesado la transición política, se plasmaría en la Constitución de 1978. A partir de entonces la realidad escolar no sería la misma en España, ${ }^{81}$ y tras su derogación hemos asistido a una corriente reformista de la educación por parte de los distintos gobiernos democráticos justificada, en la mayoría de los casos, por razones de carencias del sistema educativo en ese momento en vigor. En fin, se diría que actualmente seguimos inmersos en esa corriente reformista que alimentada por la racionalidad tecnoburocrática suscita en la comunidad educativa y en la sociedad en general una gran inquietud hasta el punto que se reclame más

\footnotetext{
79 Félix Ortega, «La ideología de la reforma educativa de 1970», 39.

80 En este sentido, destacamos el reciente análisis de Antonio Viñao Frago, «La Ley General de Educación de 1970. ¿Final de una etapa? ¿Comienzo de otra?», en Modernización educativa y socialización política. Contenidos curriculares y manuales escolares en España durante el tardofranquismo y la Transición democrática, ed. Manuel Ferraz Lorenzo (Madrid: Universidad de La Laguna y Editorial Morata, 2020), 125-149.

81 Alejandro Tiana Ferrer, «La Ley General de Educación veinte años después. Elementos para una revisión», Revista de Educación n. ${ }^{\circ}$ ext. «La Ley General de Educación veinte años después» (1992): 9.
} 
estabilidad para el sistema escolar. Esta «preocupante inestabilidad» legislativa que señala Puelles Benitez ${ }^{82}$ no es una cuestión baladí si tenemos en cuenta el escaso tiempo que han permanecido en vigor las leyes educativas posteriores, es decir, las aprobadas ya en tiempos de la transición democrática hasta la actualidad. ${ }^{83}$ Todo ello, como es bien sabido, alimentado por las diferencias en la determinación del estatus de la enseñanza pública y la enseñanza privada que han abocado a ese inquietante baile de leyes que hace inviable cualquier reconocimiento de los esfuerzos ya realizados en materia de política educativa, a la vez que refleja un cierto desencanto y esceptismo en la opinión pública en general.

\section{Nota sobre la autora}

Patricia Delgado-Granados es doctora, con mención europea, en Filosofía y Ciencias de la Educación, y Premio Extraordinario de Doctorado por la Universidad de Sevilla. Profesora titular de Universidad en el Dpto. de Teoría e Historia de la Educación y Pedagogía Social de la Universidad de Sevilla. Sus líneas de investigación se centran en: historia de la educación española en la etapa contemporánea, política educativa y pensamiento educativo. El resultado de estas investigaciones los ha dado a conocer en proyectos de investigación, libros, ponencias y artículos publicados en revistas especializadas. Ha realizado estancias de investigación y docencia en diversas Universidades internacionales (Ciudad de México, Londres, Messina, Roma, Ferrara, Salzburgo, Lisboa y Bari) y es integrante del grupo de investigación Historia, Memoria y Patrimonio de la Educación. Ha ocupado los puestos de secretaria del Dpto. de Teoría e Historia de la Educación y Pedagogía Social y de vicedecana de Ordenación Académica de la Facultad de Ciencias de la Educación de la Universidad de Sevilla. Actualmente es miembro de la Junta Directiva de la Sociedad Española de Historia de la Educación (SEDHE), Secretaria de la revista Historia y Memoria de la Educación y forma parte del Consejo Asesor de la colección «Clásicos de la Educación» de la Editorial Morata.

\footnotetext{
82 Manuel de Puelles Benítez, «Reflexiones sobre cuarenta años de educación en España o la irresistible seducción de las leyes», Historia y Memoria de la Educación 3 (2016): 17.

83 Precisamente en estos meses se ha puesto en marcha en el Congreso de los Diputados el proceso que dará lugar a una ley educativa que sustituirá a la LOMCE... Es decir, sería la octava ley orgánica de educación aprobada en democracia.
} 


\section{REFERENCIAS}

Alted Vigil, Alicia. La política económica en España durante el régimen de Franco: una perspectiva histórica. Madrid: UNED, 1986.

Althusser, Louis. Ideología y aparatos ideológicos del Estado. Freud y Lacan. Nueva Visión: Buenos Aires, 1988.

Aróstegui Sánchez, Julio. «La historiografía sobre la España de Franco. Promesas y debilidades». Historia Contemporánea 7 (1992): 77-100.

Aróstegui Sánchez, Julio. La investigación histórica: teoría y método. Barcelona: Crítica, 1995.

Beas Miranda, Miguel. «Formación del magisterio y reformas educativas en España: 1960-1970». Revista de currículum y Formación del profesorado 14, no. 1 (2010): 397-414.

Benjamin, Walter. Escritos autobiográficos, trad. Teresa Rocha Marco. Madrid: Alianza Editorial, 1996.

Blat Gimeno, Amparo. "El Llibre Blanc i la Llei General d’Educació de 1970 segons Blat Gimeno”. Educació i Història 36 (2020): 161-175.

Cabrera Montoya, Blas. "Políticas educativas en clave histórica: la LOGSE de 1990 frente a la LGE de 1970». TEMPORA 10 (2007): 147-181.

Cabrera Montoya, Blas. «La obediencia de las reformas educativas a las políticas educativas internacionales. Breve historia de cómo se hace camino desde la Ley Orgánica General del Sistema Educativo (LOGSE) de 1990 a la Ley Orgánica de Mejora de la Calidad Educativa (LOMCE) de 2013». Historia y Memoria de la Educación 3 (2016): 171-195.

Carr, Edward H. ¿Qué es la historia? Barcelona: Ariel Historia, 2003.

Carreras, Albert y Xavier Tafunell. Estadísticas históricas de España. Siglos XIXXX. 3 volúmenes. Madrid: Fundación BBVA, 2006.

Cruz Orozco, José Ignacio. Prietas las filas. Las Falanges Juveniles de Franco. Valencia: Publicacions de la Universitat de Valencia, 2012.

Delgado Granados, Patricia. Las enseñanzas profesionales en la dictadura franquista (1955-1970). Sevilla: Kronos, 2003.

Delmiro Coto, Benigno. La rebelión de la cultura en Asturias: Las sociedades culturales frente al franquismo. Oviedo: KRK Ediciones, 2019.

Díez Hochleitner, Ricardo, Joaquín Tena Artigas y Marcelino García Cuerpo. La reforma educativa española y la educación permanente. París: UNESCO, 1977.

Díez Hochleitner, Ricardo. "La reforma educativa de 1970. Su pequeña historia», en Simposium Internacional sobre Educación e Ilustración (Madrid: MEC, 1988), 477-498.

Díez Hochleitner, Ricardo. «La reforma educativa de la Ley General de Educación de 1970. Datos para una crónica». Revista de Educación n. ${ }^{\circ}$ ext. «La Ley General de Educación veinte años después» (1992): 261-278. 
Domènech Sampere, Xavier. «La formación de la clase obrera bajo el franquismo. Nuevos debates». Ayer 79, no. 3 (2020): 283-296.

Escolano Benito, Agustín. «Discurso ideológico, modernización técnica y pedagógica crítica durante el franquismo». Historia de la educación: Revista interuniversitaria 8 (1989): 7-28.

«Los comienzos de la modernidad pedagógica en el franquismo (1951-1964)». Revista española de Pedagogía 50, no. 192 (1992): 289-310.

Espigado Tocino, Gloria y Blas Cabrera Montoya. «Las leyes educativas de la democracia en España a examen (1980-2013)». Historia y Memoria de la Educación 3 (2016): 7-14.

Estapé, Fabián. De tots colors: Memories. Barcelona: Editions 62, 2000.

Fernández Cantos, José Luis y Joaquín G. Carrasco. Ley General de Educación. Espíritu y realidad de la reforma educativa española. Salamanca: Ediciones Sígueme, 1971.

Fernández de la Mora, Gonzalo. El crepúsculo de las ideologías. Madrid: Espasa Calpe, 1986.

Fernández Soria, Juan Manuel. Educación, socialización y legitimación política (España 1931-1970). Valencia: Tirant lo Blanch, 1998.

Fernández Soria, Juan Manuel. «Usos y dimensión moral de la memoria y el olvido en la historia de la educación». Sarmiento 10 (2006): 25-58.

García Delgado, José Luis. La economía española durante el franquismo. Barcelona: Temas para el Debate, 1995.

Giménez Martínez, Miguel Ángel. El Estado franquista. Fundamentos ideológicos, bases legales y sistema institucional. Madrid: Centro de Estudios Políticos y Constitucionales, 2014.

Informe FOESSA. Informe sociológico sobre la situación social en España. Madrid: Euroamérica, 1966.

Jiménez Jaén, Marta. La Ley General de Educación y el movimiento de enseñantes. Un análisis sociológico. La Laguna: Universidad de La Laguna, 2005.

Lerena Alesón, Carlos. Escuela, ideología y clases sociales. Barcelona: Ariel, 1976. Mannheim, Karl. «El problema de las generaciones», REIS 62 (1993): 193-242.

Martín Criado, Enrique. «El idealismo como programa y como método de las reformas escolares». El nudo de la Red 3, no. 4 (2004): 18-32.

Mayordomo Pérez, Alejandro. «La transición a la democracia: educación y desarrollo político». Historia de la Educación: Revista Interuniversitaria 21 (2002): 19-47.

Mayordomo Pérez, Alejandro. «Aproximación a enfoques y tiempos de la política educativa», en Estudios sobre la política educativa durante el franquismo, editado por Alejandro Mayordomo Pérez, 7-39. Valencia: Universitat de València, 1999.

MEC. La educación en España. Bases para una política educativa. Madrid: MEC, 1969. 
MEN-OCDE, Las necesidades de educación y el desarrollo económico-social de España. Madrid: MEN-OCDE, 1963.

Molinero, Carmen e Pere Ysàs. La anatomía del franquismo. De la supervivencia a la agonía, 1945-1977. Barcelona: Crítica, 2008.

Moradiellos García, Enrique. «Franco, el Caudillo: origen y perfil de una magistratura política carismática». Historia y Política 35 (2016): 261-287.

Morgenstern de Finkel, Sara. «Transición política, práctica educativa y formación del profesorado». Revista de Educación 284 (1987): 77-99.

Morgenstern de Finkel, Sara. «The scenario of the Spanish Educational Reform». En Understanding Educational Reform in global context. Economy, ideology and the State, editado por Mark Ginsburg, 151-178. Nueva York: Garland Publishing, 1991.

O’Malley, Pamela. «La Alternativa». Revista de Educación n. ${ }^{\circ}$ ext. «La Ley General de Educación veinte años después» (1992): 325-337.

O’Malley, Pamela. «Turning point: the 1970 Education Act». En Education Reform in Democratic Spain, International Developments in School Reform, editado por Oliver Boyd-Barret, 25-31. New York: Routledge, 1995.

La educación en la España de Franco. Madrid: Gens, 2008.

Oltra, Benjamín y De Miguel, Amando. «Bonapartidismo y catolicismo: una hipótesis sobre los orígenes ideológicos del franquismo». Papers: Revista de Sociologia 8 (1978): 53-102

Ortega, Félix. «La ideología de la reforma educativa de 1970». Revista de Educación n. ${ }^{\circ}$ ext. «La Ley General de Educación veinte años después» (1992): 31 46.

Ortega, Félix. El mito de la modernización. Las paradojas del cambio social. Barcelona: Anthropos, 1994.

Pozo Andrés, María del Mar del y Sjaak Braster. «The Reinvention of the New Education Movement in the Franco Dictatorship (Spain, 1936-1976)». Paedagogica Historica 42, no. 1-2 (2006): 109-126.

Preston, Paul. Franco: Caudillo de España. Madrid: Debate, 2015.

Puelles Benítez, Manuel de. «Oscilaciones de la política educativa en los últimos cincuenta años: Reflexiones sobre la orientación política de la educación». Revista Española de Pedagogía 192 (1992): 311-319.

Puelles Benítez, Manuel de. «Tecnocracia y política en la reforma educativa de 1970». Revista de Educación n. ${ }^{\circ}$ ext. "La Ley General de Educación veinte años después» (1992): 13-29.

Puelles Benítez, Manuel de. «Evolución de la educación en España durante el franquismo». En Historia de la Educación. Edad Contemporánea, editado por Alejandro Tiana, Gabriela Ossenbach y Florentino Sanz, 289-314. Madrid: UNED, 2002. 
Puelles Benítez, Manuel de. Política y educación en la España contemporánea. Madrid: UNED, 2011.

Puelles Benítez, Manuel de. "Reflexiones sobre cuarenta años de educación en España o la irresistible seducción de las leyes». Historia y Memoria de la Educación 3 (2016): 15-44.

Ramírez Jiménez, Manuel. España 1939-1975. Régimen político e ideología. Barcelona: Labor, 1978.

Raymond, Carr y Pablo Fusi, Juan. España, de la dictadura a la democracia. Barcelona: Planeta, 1979.

Rebollo Torío, Miguel Ángel. Vocabulario político republicano y franquista, 19311971. Valencia: Fernando Torres Editor, 1978.

Riquer, Borja de. La dictadura de Franco. Volumen 9. Barcelona: Crítica-Marcial Pons, 2010.

Ruiz-Giménez, Joaquín. «Educación y socialización». Cuadernos para el Diálogo 79 (1970): 16-18.

Ruiz Carnicer, Miguel Ángel. El Sindicato Español Universitario (SEU), 19391965. La socialización politica de la juventud universitaria en el franquismo. Madrid: Siglo XXI, 1996.

Santamaría Ossorio, Julián (comp.). En transición a la democracia en el Sur de Europa y América Latina. Colección monográfica. Madrid: CSIC, 1982.

Sevilla Moreno, Diego. "La difícil traslación a una política de gobierno de un acuerdo constitucional forzado. La Unión de Centro Democrático y su malograda Ley Orgánica del Estatuto de Centros Escolares (LOECE) de 1980». Historia y Memoria de la Educación, 3 (2016): 45-70.

Soto Carmona, Álvaro y Pedro A Martínez Lillo. «La naturaleza del franquismo». El País, 8 de junio de 2011.

Soto Carmona, Álvaro. «Los pactos en las transiciones democráticas. España: 1975-1982». APORTES 93, no. 1 (2017): 221-243.

Tena Artigas, Antonio. «La Educación y el primer Plan de Desarrollo». Revista de Educación 180 (1966): 26-31.

Tiana Ferrer, Alejandro. «La Ley General de Educación veinte años después. Elementos para una revisión». Revista de Educación n. ${ }^{\circ}$ ext. "La Ley General de Educación veinte años después» (1992): 7-10.

Tiana Ferrer, Alejandro. «El proceso de universalización de la enseñanza secundaria en España en la segunda mitad del siglo XX: una aproximación estadística». Bordón 6, no. 4 (2013): 149-165.

VV. AA. Informe del Banco Internacional de Reconstrucción y Fomento: el desarrollo económico de España. Madrid: Oficina de Coordinación y Programación Económica, 1962.

Vega Gil, Leoncio. « La reforma educativa en España (1970-1990) ». Educar em revista 13 (1997): 101-132. 
Viñao Frago, Antonio. «La educación general básica. Entre la realidad y el mito». Revista de Educación n. ${ }^{\circ}$ ext. "La Ley General de Educación veinte años después» (1992): 47-71.

Viñao Frago, Antonio. «La educación en el franquismo (1936-1975)». Educar em Revista 51 (2014): 19-35.

Viñao Frago, Antonio. Escuela para todos. Educación y modernidad en la España del siglo XX. Madrid: Marcial Pons, 2004.

Viñao Frago, Antonio. «Ayer y hoy de la educación en España. Memorias y desmemorias». En Lecciones contra el olvido. Memoria de la educación y educación de la memoria, editado por Carlos Lomas, 23-60. Madrid: Octaedro, 2011.

Viñao Frago, Antonio. «La Ley General de Educación de 1970. ¿Final de una etapa? ¿Comienzo de otra?». En Modernización educativa y socialización política. Contenidos curriculares y manuales escolares en España durante el tardofranquismo y la Transición democrática, editado por Manuel Ferraz Lorenzo, 125-149. Madrid: Universidad de La Laguna y Editorial Morata, 2020.

Ysàs, Pere. «El Consejo Nacional del Movimiento en el franquismo tardío». En Falange. Las culturas políticas del fascismo en la España de Franco (19361975), editado por Miguel Ángel Ruiz Carnicer, 365-381. Zaragoza: Institución Fernando el Católico, 2013. 